J. Clin. Chem. Clin. Biochem.

Vol. 25, 1987, pp. 457-466

(C) 1987 Walter de Gruyter \& Co. Berlin - New York

\title{
Renal and Hepatic Nitrogen Metabolism in Systemic Acid Base Regulation
}

\author{
By W. G. Guder \\ Institut für Klinische Chemie, Städtisches Krankenhaus München-Bogenhausen, München \\ D. Häussinger and W. Gerok
}

Medizinische Universitätsklinik Freiburg i. Br.

(Received January 23, 1987)

Summary: Renal and hepatic nitrogen metabolism are linked by an interorgan glutamine flux, coupling both renal ammoniagenesis and hepatic urea production to systemic acid-base regulation. Reconsideration of established pathways and recent observations led to a conceptional change with a movement from a twoorgan concept (lungs and kidney) of acid-base balance to a three-or-more organ concept (lungs, kidney, liver). This development implies new regulatory sites of systemic pH control and consequently a new pathophysiological understanding of derangements of acid-base homeostasis.

In this new concept the urea cycle regulates the removal of metabolically generated bicarbonate during a protein load in a $\mathrm{pH}$ - and bicarbonate-dependent manner. This is related to a switch of hepatic ammonium detoxication from urea to glutamine synthesis in metabolic acidosis, and vice versa in alkalosis. An adaptive increase in the renal capacity for glutamine deamidation and deamination and for ammonium excretion leads to a proportional decrease in renal urea excretion at the expense of ammonium in acidotic conditions.

The present review summarizes experimental data and clinical implications resulting from this new concept, which was also the subject of a recent Conference of the German Society for Clinical Chemistry "Mechanisms and Control of $\mathrm{pH}$ Homeostasis".

\section{Introduction}

Alterations in nitrogen metabolism in connection with acid base disturbances are well known phenomena in experimental clinical medicine $(1-4)$. Thus, it was observed in the last century that ammonium? excretion into the urine increases in diabetic acidosis with a simultaneous decrease in urea excretion. Likewise, starvation led to a considerable decrease in urea excretion with a concomitant increase in renal ammonium production in parallel with ketosis (5). This switch from urea to ammonium excretion is

1) In the present review the term "ammonium" is used for both $\mathrm{NH}_{3}$ and $\mathrm{NH}_{4}^{+}$. observed in carni- and omnivores (2). The ability of herbivores to excrete increased amounts of ammonium in acidosis is apparently impaired, but it is restored when these animals are kept on protein diet (6). It is now evident that glutamine-nitrogen is the most important precursor of renal ammoniagenesis (3).

Much effort has been devoted over decades to elucidate the mechanism of these acid-base-induced alterations of nitrogen metabolism and their role in the regulation of systemic $\mathrm{pH}$ in mammals. The fundamental work of Pitts $(3,4)$ showed that renal ammonium excretion is associated with the generation of bicarbonate. 


\section{The conceptional change}

Systemic $\mathrm{pH}$ regulation was seen to involve two principal organs: the lungs, which adjust the $\mathrm{pCO}_{2}$ and the kidneys excreting acid or generating bicarbonate. The kidney of omnivorous mammals provides several mechanisms to counteract the development of metabolic acidosis: proximal tubular bicarbonate reabsorption is of basic importance, since it has a capacity to reabsorb filtered bicarbonate nearly quantitatively. In addition, proton secretion, a principal function of the late distal convoluted tubule and the collecting duct, specifically adds protons to the tubular fluid thus determining the final urine $\mathrm{pH}$. The ability to excrete "titratable acid" is limited by the amount of buffer delivered to the distal nephron, since the ability of the distal nephron to lower the urine $\mathrm{pH}$ is limited by the transluminal $\mathrm{H}^{+}$gradient. In addition to phosphate, this buffer consists mainly of ammonium derived from renal glutamine breakdown. (4) According to the traditional view, renal glutamine breakdown produces $\mathrm{NH}_{3}$, which diffuses into the tubular lumen and fixes a proton, thus enhancing the gradient-limited proton secretion (fig. 1 a). According to this concept, the kidney generates one mole bicarbonate per mole $\mathrm{NH}_{4}^{+}$excreted.

This traditional view, however, has been questioned, since at physiological $\mathrm{pH}$, hydrolysis of glutamine will yield $\mathrm{NH}_{4}^{+}$instead of $\mathrm{NH}_{3}$ (because the $\mathrm{pK}$ value of the $\mathrm{NH}_{3} / \mathrm{NH}_{4}^{+}$system is 9.3 ), which can no longer fix a proton $(7-11)$. Thus the step of renal excretion of ammonium ions represents no net proton excretion and alternative explanations for the observed facts become necessary. Based on these considerations, first raised by Bourke and Atkinson (7-9), the tradi- tional view was modified $(12-15)$. This modification accepted that glutamine hydrolysis will yield $\mathrm{NH}_{4}^{+}$ instead of $\mathrm{NH}_{3}$, but pointed out that simultaneously the flux of 2-oxoglutarate derived from glutamine into either the oxidative or the gluconeogenic pathway will consume 2 protons, resulting again in the renal production of 2 moles $\mathrm{HCO}_{3}^{-}$per mole oxoglutarate consumed (fig. $1 \mathrm{~b}$ ). Thus, the classical view including this important revision seemed essentially to be correct. However, this revised view was criticized (11) because the glutamine-derived oxoglutarate metabolism, which indeed will yield $\mathrm{HCO}_{3}^{-}$production by the kidney, will not affect total body bicarbonate homeostasis, because the oxoglutarate metabolized in the kidney is at least withdrawn from another (i.e. glutamine-supplying) organ. Therefore alternative explanations for the long-known facts became necessary. This new concept, involving hepatic ammonium metabolism is schematically depicted in figure 2 .

According to Atkinson and Bourke (9) the complete oxidation of carbohydrates and fat yields as the only products $\mathrm{CO}_{2}$ and water. Both are excreted via the lungs and kidneys. Complete oxidation of protein, however, yields in addition $\mathrm{HCO}_{3}^{-}$and $\mathrm{NH}_{4}^{+}$in almost stoichiometric amounts. In man, ingestion of an average of $100 \mathrm{~g}$ protein per day results in the daily formation of about 1 mole each of $\mathrm{HCO}_{3}^{-}$and $\mathrm{NH}_{4}^{+}$. Such a high amount of $\mathrm{HCO}_{3}^{-}$cannot be excreted via the kidneys in view of the limited urine volume. The major pathway for elimination of metabolically generated bicarbonate is hepatic urea synthesis consuming $\mathrm{NH}_{4}^{+}$and $\mathrm{HCO}_{3}^{-}$in the same stoichiometry as they are produced during protein breakdown (7-11) (fig. 2). a

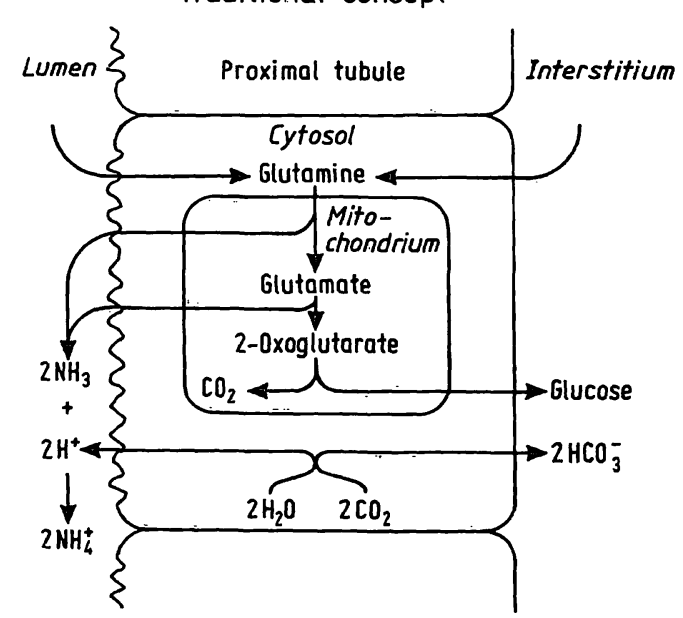

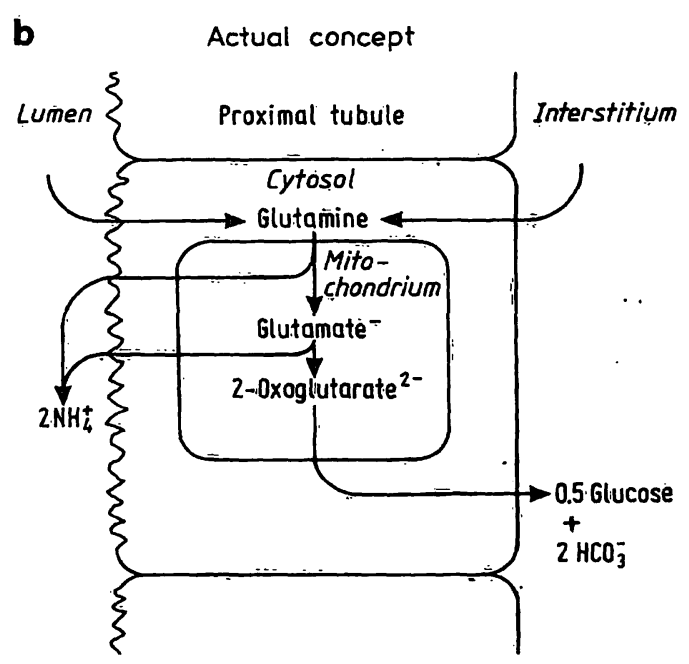

Fig. 1. The traditional concept (a): renal ammoniageneses is accompanied by new bicarbonate formation by the kidney. The recent modification (b) accepts $\mathrm{NH}_{4}^{+}$as the product of renal glutaminase reaction with new $\mathrm{HCO}_{3}^{-}$being generated during the metabolism of 2-oxoglutarate. 


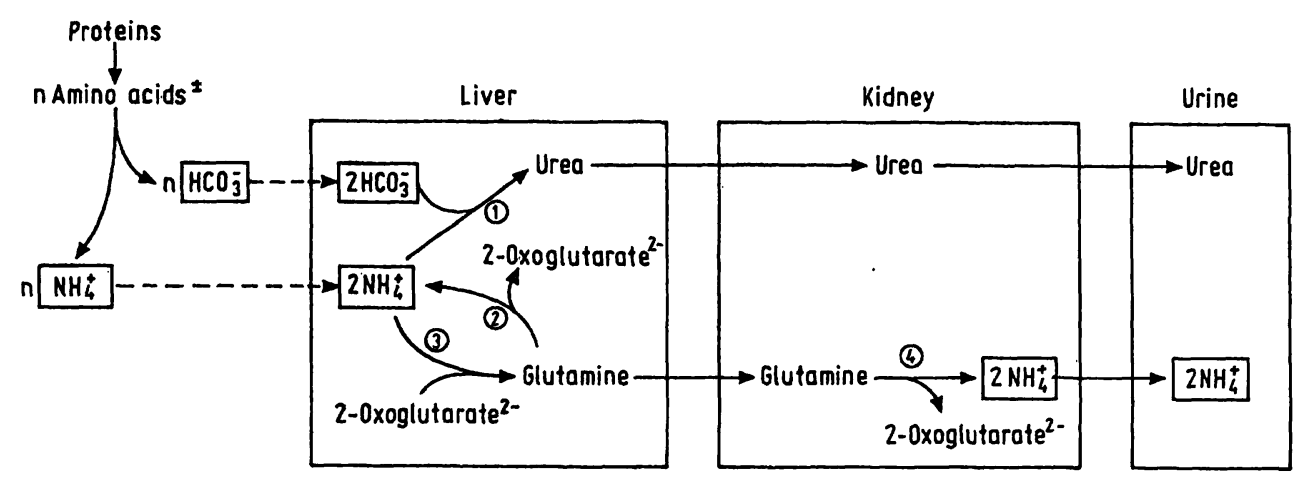

Fig. 2. The modern concept of systemic acid-base regulation: role of the liver. Urea synthesis is the major pathway for removal of $\mathrm{HCO}_{3}^{-}$and $\mathrm{NH}_{4}^{+}$, which arise in stoichiometric amounts during protein breakdown. In acidosis, $\mathrm{HCO}_{3}^{-}$is spared when hepatic urea synthesis is decreased. $\mathrm{NH}_{4}^{+}$homeostasis is guaranteed by renal $\mathrm{NH}_{4}^{+}$excretion into urine, with glutamine serving as a non-toxic transport form of $\mathrm{NH}_{4}^{+}$between the tissues (from l.c. (11)). The numbers in circles refer to the sites of acid-base control of metabolic fluxes: (1) urea synthesis, (2) liver glutaminase, (3) liver glutamine synthetase, (4) kidney glutaminase.

\section{$2 \mathrm{HCO}_{3}^{-}+2 \mathrm{NH}_{4}^{+} \longrightarrow \longrightarrow \mathrm{Urea}+\mathrm{CO}_{2}+\mathrm{H}_{2} \mathrm{O}$}

This stoichiometry has been demonstrated experimentally in perfused liver (11).

In chemical terms hepatic urea synthesis can be viewed as an energy-consuming and irreversible neutralization reaction of the strong base $\mathrm{HCO}_{3}^{-}$by the weak acid $\mathrm{NH}_{4}^{+}$. Thus, a daily excretion of $30 \mathrm{~g}$ urea in man is equivalent to the disposal of 1 mole $\mathrm{HCO}_{3}^{-}$. Ammonium ions, however, can also be detoxified by glutamine formation, a process occurring in the liver as well as in other organs, and ammonium can be excreted into urine as such after renal hydrolysis of glutamine. Therefore, the route of hepatic nitrogen disposal by either urea or glutamine synthesis determines the rate of $\mathrm{HCO}_{3}^{-}$removal and the liver becomes an important organ in acid-base homeostasis (fig. 2). According to this view, the step of $\mathrm{NH}_{4}^{+}$ excretion by the kidney represents only an adaptation to another form of waste nitrogen excretion without affecting per se $\mathrm{pH}$ homeostasis $(8-11)$, whereas the regulatory decision in $\mathrm{pH}$ homeostasis is made in the liver by control of $\mathrm{HCO}_{3}^{-}$consumption. A reduction of hepatic urea synthesis in acidosis will therefore spare bicarbonate. Glutamine may simply be seen as a non-toxic transport form of $\mathrm{NH}_{4}^{+}$between the tissues. The conceptional change from the traditional view to that involving hepatic urea synthesis as a crucial parameter of acid base homeostasis is subject to extensive discussion in the literature $(7-18)$. This discussion is by no means semantic because this conceptional change is equivalent to a movement from a two-organ-understanding of acid base balance to a three-or-more-organ-understanding, implicating new regulatory sites in systemic acid base homeostasis.
Pathways of renal and hepatic ammonium metabolism Origin of renal ammonium

Besides a small portion of ammonium derived from filtered blood, the bulk of renal ammonium is formed metabolically in the kidney (for reviews see 1.c. (1921)). Pitts identified glutamine as the principle source of renal ammoniagenesis $(3,4)$. Luminal (filtrate) and contraluminal (plasma) glutamine can be taken up by the tubular cell. Peritubular uptake becomes increasingly important in metabolic acidosis (22), explaining why renal glutamine clearance exceeds glomerular filtration under acidotic conditions.

The enzymes responsible for renal ammonium formation are the so-called phosphate-dependent glutaminase and glutamate dehydrogenase. Both enzymes reside in the mitochondrial compartment $(23,24)$. The resulting 2-oxoglutarate is either oxidized to $\mathrm{CO}_{2}$ or converted to glucose (25). Even if all oxoglutarate enters the gluconeogenic pathway, 2 moles $\mathrm{HCO}_{3}^{-}$ are formed per mole oxoglutarate used (fig. 1 b).

Topology of glutamine metabolism and ammonium transport along the nephron

From studies on microdissected nephron segments and micropuncture studies the processes of ammoniagenesis and transport have been mapped and can be attributed to defined nephron segments $(26-31)$. Phosphate-dependent glutaminase was found in proximal and distal convoluted tubules with little activities in the straight portion and the medullary segments. In rats metabolic acidosis leads to a severalfold increase in activities in the proximal convoluted tubule only (27). These data were recently confirmed by 
direct measurement of ammonium formation from glutamine in single segments of rat nephron (28, 29). Both studies agreed that proximal and distal convoluted tubules were the only segments responding to metabolic acidosis. The relatively high activities of ammonium formation, but not of glutaminase in the pars recta segment (S 3) of the proximal tubule is explained by the high activities of brush border $\gamma$ glutamyl-transferase in this segment acting as "phosphate independent glutaminase" (28).

Interestingly, tubular ammonium is reabsorbed in the ascending limb of Henle's loop using potassium transport routes (30). This leads to an accumulation of ammonium in the inner medulla and papilla. Depending on the $\mathrm{pH}$-gradient, formed by distal tubular proton secretion, the ammonium is secreted into the collecting tubule (31). Figure 3 summarizes the mechanisms of renal ammonia excretion in a simplified scheme.

In addition the proximal straight tubule (and in some species also the proximal convoluted tubule (32)) contains glutamine synthetase. This offers the possibility that ammonium recycling can occur along the proximal tubule.

Regulation of renal ammoniagenesis and ammonium transport

In vivo, net renal glutamine uptake can be observed only in metabolic acidosis, whereas under normal acid base conditions uptake rates are compensated by simultaneous production (33). The increase in ammonium excretion appears in minutes after changes in $\mathrm{pH} / \mathrm{HCO}_{3}^{-}$when studied in the isolated perfused kidney (34). Since this is not accompanied by a change in extractable glutaminase activity, the mechanism of this acute change was postulated to be related to glutamine transport. No effects were found on the tubular and peritubular transport rates of glutamine when studied either in vivo (21) or in isolated membrane vesicles (35). Isolated renal cortical mitochondria, on the other hand, exhibited a marked $\mathrm{HCO}_{3}^{-}$dependence in their transport properties for glutamate (36). Matrix 2-oxoglutarate rapidly decreases upon acidification of the matrix space (37). Since 2-oxoglutarate and glutamate are the main physiological inhibitors of renal glutamate and glutamine deamination, respectively, the mitochondrial $\mathrm{pH}$ gradient determined by cytosolic $\mathrm{HCO}_{3}^{-}$concentration seems to be responsible for the rapid increase in glutamine entry and metabolism under conditions of acute acidosis (24). In accordance with this assumption cellular and mitochondrial 2-oxoglutarate levels fall dramatically upon acidification of the medium by decreasing bicarbonate (37).

The mechanism by which acidosis stimulates metabolism of mitochondrial 2-oxoglutarate is still a matter of speculation. 2-Oxoglutarate dehydrogenase exhibits a strong $\mathrm{Ca}^{2+}$ dependence, which on the other hand is modified by the actual $\mathrm{pH}$ (38). In addition succinate dehydrogenase flux has been shown to be accelerated in acidotic kidney mitochondria (39).

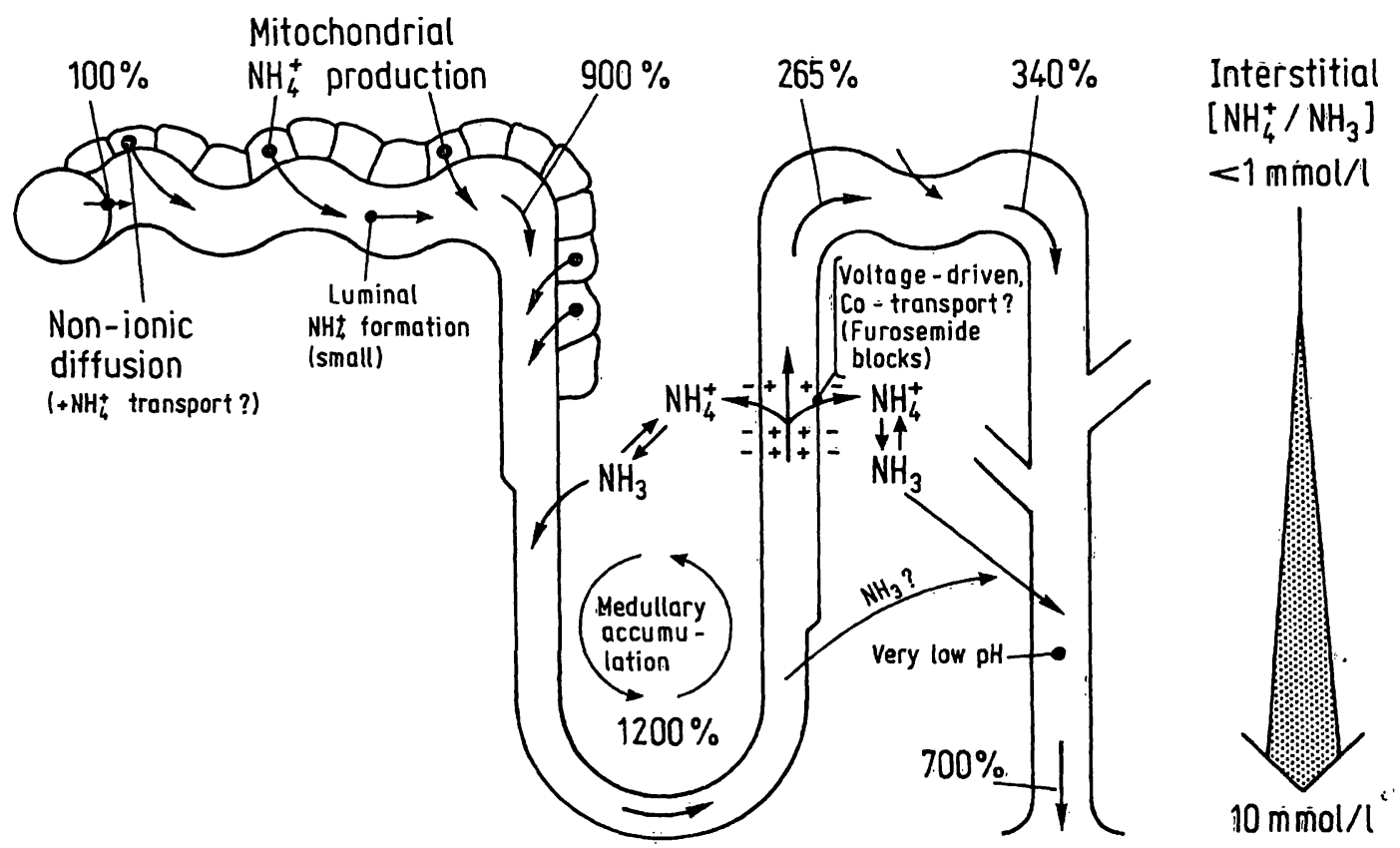

Fig. 3. Sites and mechanisms of renal ammonia excretion at acid urine pH. Proximal tubular $\mathrm{NH}_{4}^{+}$is accumulated in the papilla and passively secreted into the acidic lumen of the collecting tubule. Percent values give ammonia $\left(\mathrm{NH}_{4}^{+}+\mathrm{NH}_{3}\right)$ concentrations in comparison with that in glomerular filtrate. (reproduced with permission from 1.c. (16)). 
The further fate of glutamine carbon depends on the species studied and the actual metabolic condition. In the proximal convoluted tubule, 3 out of 5 carbons of glutamine can be converted to glucose. This coupling of gluconeogenesis to ammoniagenesis seems unique for the kidney, since renal gluconeogenesis increases in metabolic acidosis in parallel to ammoniagenesis, whereas hepatic gluconeogenesis decreases $(40,41)$. On the other hand glutamine nitrogen can be recovered as alanine and vice versa (42). This seems remarkable since alanine, the major hepatic glucogenic amino acid, is not used as a glucogenic precursor by the kidney (40). These striking differences between renal and liver gluconeogenesis make it attractive to consider a functional coupling between glucose and ammonia metabolism in both organs. In accordance with this idea, inhibition of gluconeogenesis markedly decreased ammonium excretion in the isolated kidney (43). Others, however, failed to show this tight coupling (44), indicating that the rate controlling step of renal ammoniagenesis lies before the first step of the gluconeogenic pathway. The above mentioned intramitochondrial enzymes, glutamate dehydrogenase, 2-oxoglutarate dehydrogenase and succinate dehydrogenase are directly or indirectly coupled to the respiratory chain. The rate of ATP turnover of the cell, which regulates tubular oxidative phosphorylation, therefore seems to limit the rate of proximal tubular ammoniagenesis (25). This view was strengthened by the early observations of a strong correlation between renal ammoniagenesis and oxygen consumption, whereas no correlation was detectable between oxygen uptake and gluconeogenesis (45). This is confirmed by the finding that uncoupling stimulates (46), whereas inhibition of ATP turnover (by addition of ouabain) inhibits ammonium formation from glutamine (47). Addition of alternative proximal tubular substrates like ketone bodies and lactate likewise led to a reduction of tubular glutamine metabolism in normal, but not chronically acidotic states $(40,47)$.

\section{Pathways and sites of hepatic ammonia metabolism}

In the liver acinus, urea and glutamine synthesis represent two subsequent pathways with the enzymes of urea synthesis being periportal and glutamine synthetase being perivenous (fig. 4) (48). From a kinetic point of view hepatic ammonium detoxication occurs by the sequence of a periportal low affinity, but high capacity system (ureogenesis) and a perivenous high affinity system (glutamine synthesis) for ammonium fixation (for review see 1.c. (49)). This was demonstrated in the intact rat liver (48). This structural

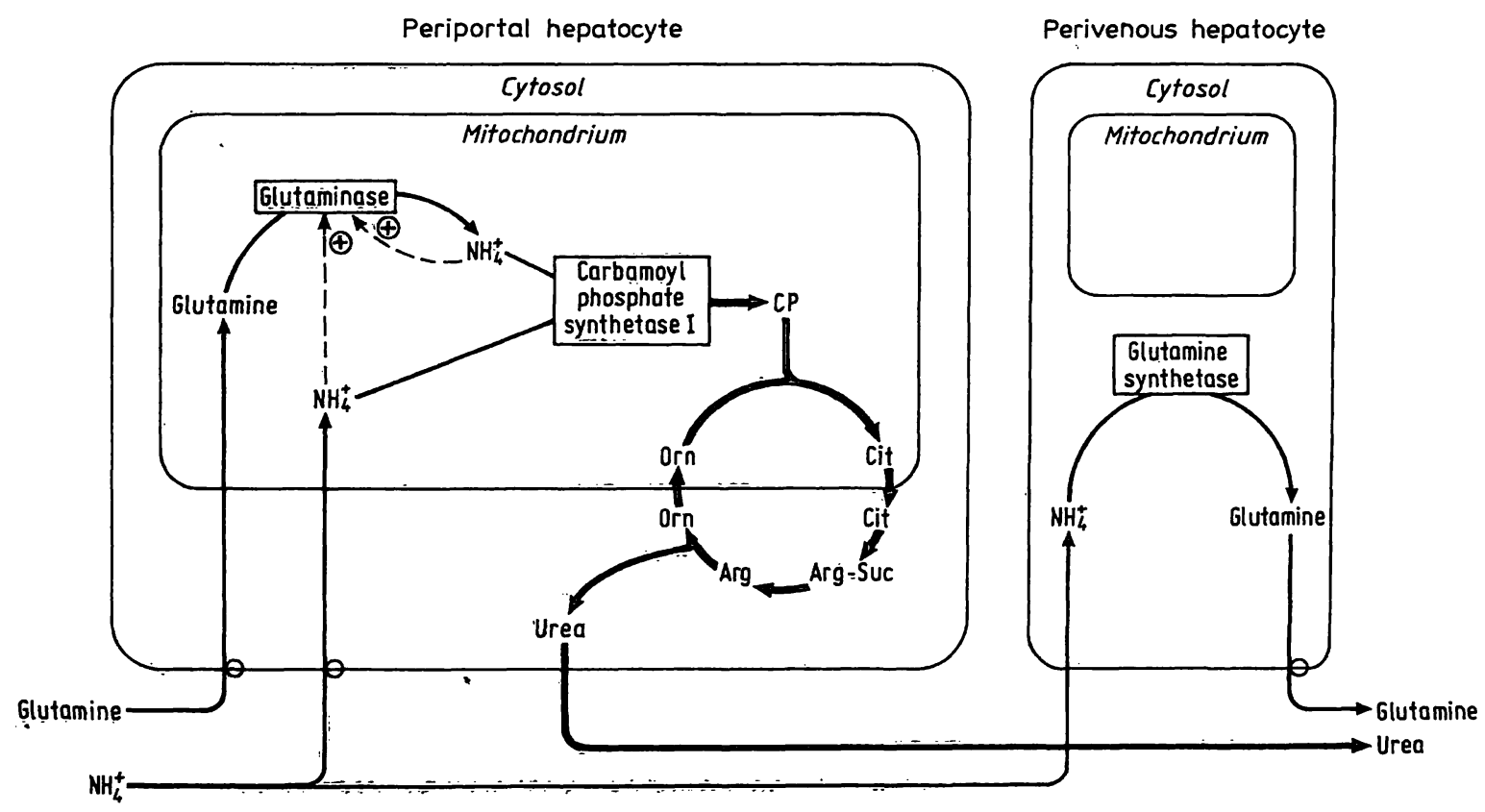

Fig. 4. Organization of hepatic ammonium and glutamine metabolism. In the liver acinus, urea synthesis (low affinity system) and glutamine synthesis (high affinity system) are two pathways for ammonium detoxication: urea cycle enzymes and glutamine are found in periportal hepatocytes, whereas glutamine synthetase is perivenous. Glutaminase flux determines the intramitochondrial ammonium supply for carbamoylphosphate synthetase, the rate-controlling enzyme of the urea cycle. Glutaminase acts as an amplification system for the mitochondrial ammonium concentration, because the enzyme is activated by its product ammonium. Periportally consumed glutamine is resynthesized by perivenous glutamine synthetase, which has a high affinity for ammonium. By means of this intercellular glutamine cycle, i.e. periportal glutamine breakdown and perivenous resynthesis at a normal pH 7.4, portal ammonium is completely converted into urea without net glutamine turnover. 
and functional organization of the two pathways for ammonium detoxication implies that any flux change through the urea cycle will determine the substrate supply for perivenous glutamine synthesis.

Hepatic glutaminase is localized in the same periportal compartment as urea synthesis (48) and the role of this enzyme is seen in regulating the intramitochondrial ammonium provision for carbamoylphosphate synthetase, the rate-controlling step of urea synthesis under physiological conditions (fig. 4) (50). In this respect mitochondrial glutaminase acts as an amplification system for portal ammonium, because this enzyme is activated by its product ammonium (for review see 1.c. (51)) and exhibits a $K_{\mathrm{a}}$ (ammonium) in the intact liver near the physiological portal ammonium concentration of $0.2-0.3 \mathrm{mmol} / \mathrm{l}(52)$. In analogy to glutaminase, mitochondrial carbonic anhydrase, a new isoenzyme, was shown to provide mitochondrial bicarbonate (in addition to a non-enzymatic bicarbonate formation), the other substrate for carbamoylphosphate synthetase (53). In the presence of physiological extracellular bicarbonate and carbon dioxide concentrations, about $50 \%$ of the urea cycle flux depends on the activity of carbonic anhydrase (53). Although the extracellular bicarbonate and carbon dioxide concentrations are normally high, this involvement of carbonic anhydrase is not surprising in view of the restricted permeability of the mitochondrial membrane to bicarbonate in contrast to carbon dioxide (54).

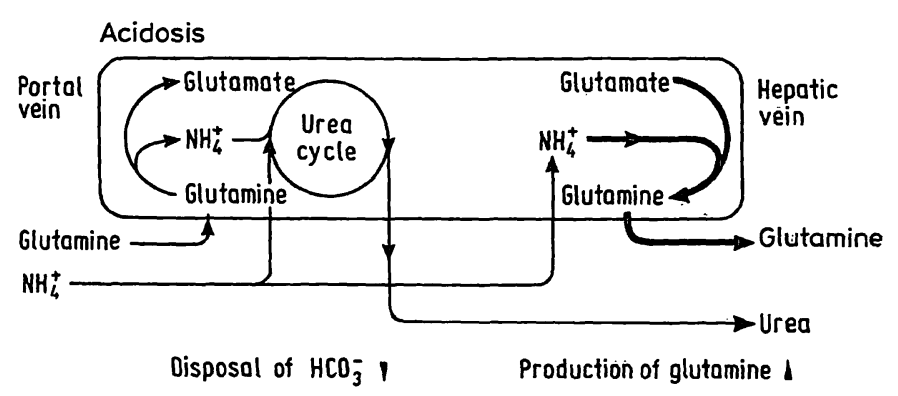

b Acidosis

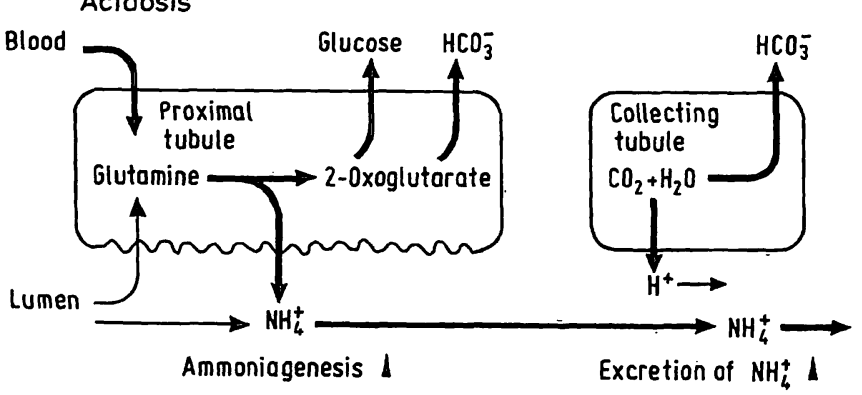

\section{Regulation by acid base state}

By means of the intercellular glutamine cycle $(10,48$, 49) i. e. simultaneous periportal glutamine hydrolysis and perivenous glutamine resynthesis, portal ammonium is completely converted into urea, despite the low portal ammonium concentration. This situation of a complete conversion of portal ammonium into urea without an accoompanying net turnover of glutamine by the liver characterizes the well-balanced $\mathrm{pH}$ homeostasis $(10,48)$. However, during metabolic acidosis there is an inhibition of glutaminase flux and increase in glutamine synthetase flux̃, resulting in a decrease of hepatic urea synthesis at the expense of a net glutamine formation (fig. 5 a). Such a device should favour $\mathrm{pH}$ homeostasis by sparing bicarbonate and ammonium which are excreted into the urine as such with glutamine being the non-toxic transport form for ammonium between liver and kidney (fig. 2). Several mechanisms have been detected so far, which adjust the rate of hepatic urea formation (being equivalent to hepatic bicarbonate removal) to the requirements of acid-base homeostasis (fig. 6). This acid-base control of urea cycle flux is achieved by regulation of substrate provision for mitochondrial carbamoylphosphate synthetase, the rate-controlling step in urea synthesis, whereas no control of the five urea cycle enzymes by acid-base homeostasis has so far been detected (53). The acid-base parameters sensed for adjusting bicarbonate disposal via urea synthesis include the extracellular $\mathrm{pH}$, and the abso-
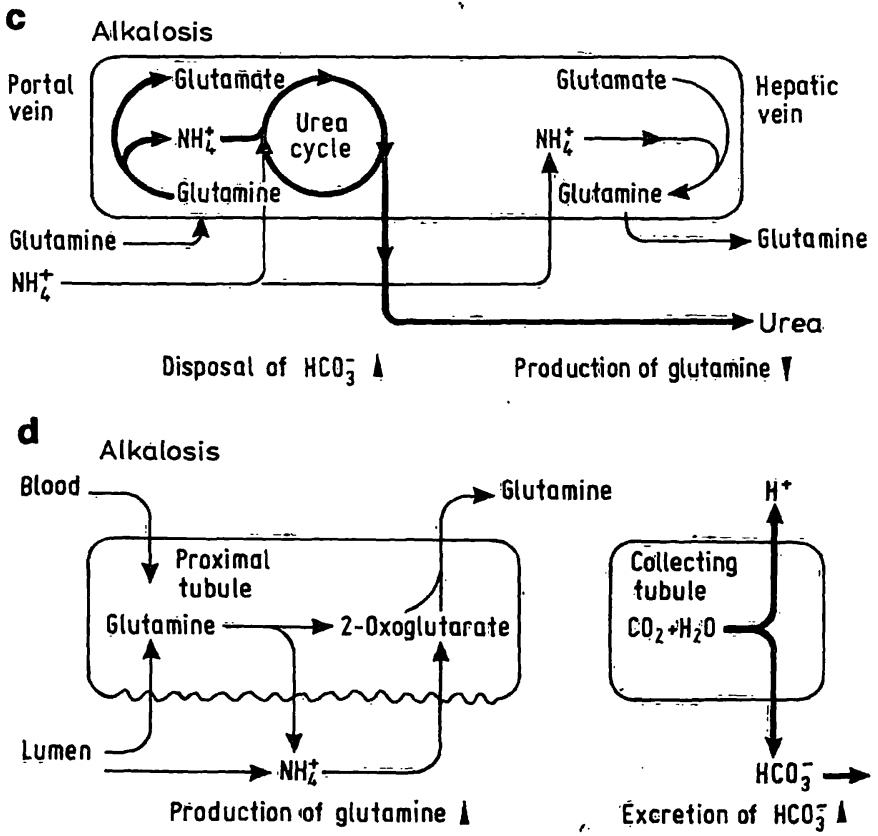

Fig. 5. Role of the intercellular glutamine cycle in acid-base disturbances.

(a, b) Acidosis: Glutaminase flux is decreased, resulting in an inhibition of urea cycle flux, and glutamine synthesis is increased. Thus $\mathrm{HCO}_{3}^{-}$is spared and $\mathrm{NH}_{4}^{+}$are increasingly converted to glutamine, the substrate for renal ammoniagenesis. (c, d) Alkalosis: Glutaminase flux is increased, stimulating urea synthesis and therefore $\mathrm{HCO}_{3}^{-}$consumption. Glutamine synthetase flux is decreased, resulting in a net glutamine uptake by the liver. Renal ammoniagenesis is decreased. 


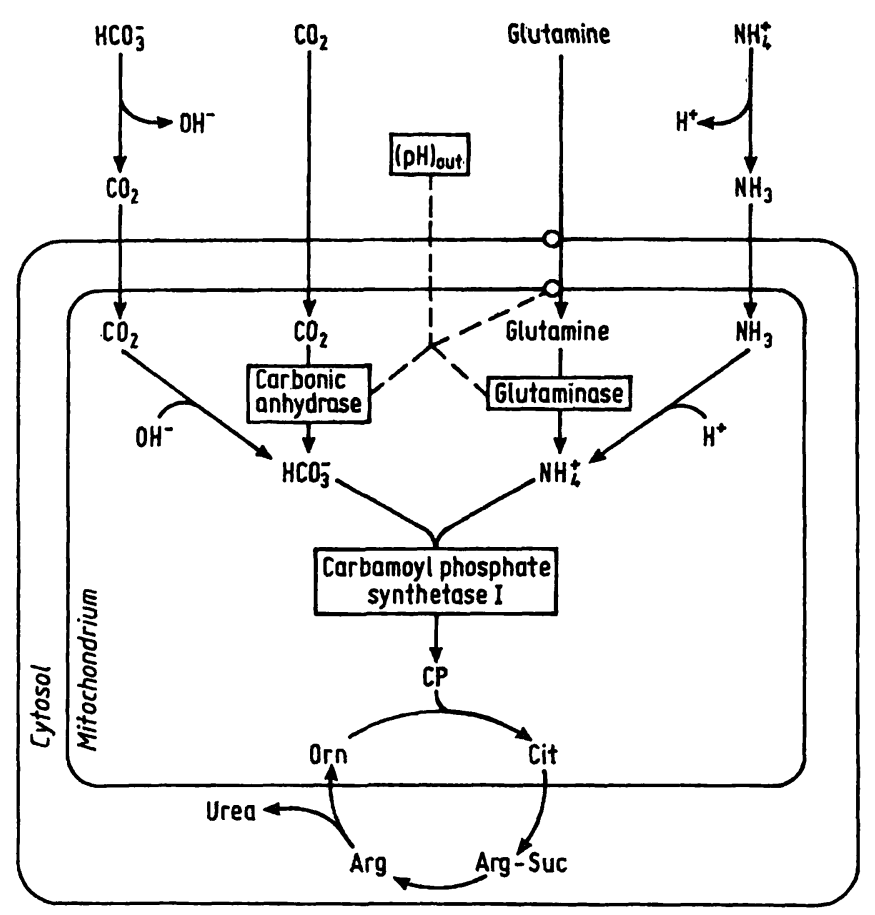

Fig. 6. Acid base control of urea synthesis. Major sites of control are the flux through glutaminase, carbonic anhydrase, glutamine transport across the plasma membrane, the free $\mathrm{NH}_{3}$ concentration and the absolute $\mathrm{CO}_{2}$ and $\mathrm{HCO}_{3}^{-}$concentrations.

lute concentrations of bicarbonate and carbon dioxide in the extracellular space (53). A decrease of the extracellular $\mathrm{pH}$ results in an inhibition of flux through glutaminase and carbonic anhydrase $(9,52$, 53), both mitochondriäl enzymes providing ammonium ions and bicarbonate for carbamoylphosphate synthetase. The $\mathrm{pH}$ dependence of these substrateproviding reactions is highly sensitive: raising the extracellular $\mathrm{pH}$ from 7.1 to 7.4 is followed by a 5 fold increase of glutaminase flux and a 3-fold increase in carbonic anhydrase flux $(10,52,53)$. The control of urea cycle flux via the $\mathrm{pH}$ dependent activity of carbonic anhydrase is modified by the absolute bicarbonate and carbon dioxide concentrations in the extracellular space, which determine the uncatalysed bicarbonate formation inside the mitochondria and thereby the extent of carbonic anhydrase dependence of urea synthesis (53). This may explain the different response of urea synthesis in metabolic and respiratory acidosis. In metabolic acidosis the extracellular concentrations of carbon dioxide and bicarbonate are decreased and urea synthesis is increasingly (up to $90 \%$ ) dependent on carbonic anhydrase-catalysed bicarbonate formation inside the mitochondria, which is strongly controlled by $\mathrm{pH}$. Consequently urea synthesis and therefore bicarbonate removal decrease and portal ammonium is increasingly converted into glutamine. In respiratory acidosis, the extracellular concentrations of bicarbonate and carbon dioxide are increased and the uncatalysed bicarbonate formation inside the mitochondria will increasingly cover the bicarbonate requirements of urea synthesis. Thus, the $\mathrm{pH}$ control of urea synthesis via carbonic anhydrase activity is overridden in respiratory acidosis. In this context, it is of interest to note that chronic respiratory acidosis in vivo is not accompanied by a decrease in urea excretion at the expense of renal ammonium excretion, as it is in chronic metabolic acidosis (4). Besides determining the susceptibility of urea synthesis to carbonic anhydrase-mediated control by $\mathrm{pH}$, the absolute extracellular bicarbonate and carbon dioxide concentrations affect urea synthesis even at a constant extracellular $\mathrm{pH}$ of 7.4 (53). In the absence of an extracellular bicarbonate buffer, urea synthesis from portal ammonium is almost completely inhibited, indicating that carbon dioxide derived from the various intramitochondrial dehydrogenase reactions is not sufficient to maintain urea synthesis. At a constant extracellular $\mathrm{pH}$ of 7.4 , reduction of the extracellular bicarbonate and carbon dioxide concentrations is followed by a decrease in urea synthesis (53). Another mechanism which contributes to the $\mathrm{pH}$ sensitivity of hepatic urea synthesis is the decrease of the free $\mathrm{NH}_{3}$ concentration in acidosis (55), since recent evidence suggests $\mathrm{NH}_{3}$ to be the actual substrate of carbamoylphosphate synthetase (56). Furthermore, decreased glutamine concentration gradients across the plasma membrane of hepatocytes in acidosis point to the glutamine transport system as another site of acid-base control of urea synthesis (Sies, H., Soboll, S. \& Häussinger, D. (1987) Z. Gastroenterol., in press). Urea synthesis is not only regulated by the parameters of the acid-base state, but also by the ammonium supply. Thus, even during metabolic acidosis an experimental ammonium chloride load in vivo will cause a rise in hepatic urea synthesis, thereby worsening the $\mathrm{pH}$ derangement, but preventing lethal hyperammonaemia. It is clear that such an experimental ammonium-stimulation of urea synthesis regardless the acid-base status is not against a role of urea synthesis in $\mathrm{pH}$ regulation (16, 17). The role of the liver may be compared with that of the lungs in systemic $\mathrm{pH}$ regulation: similarly, as ventilation stabilizes the $\mathrm{pCO}_{2}$ and also the $\mathrm{pO}_{2}$, hepatic urea synthesis serves two functions, namely maintainance of bicarbonate and ammonium homeostasis, and under extreme experimental situations one of these functions can no longer be maintained. 


\section{Integrated interorgan regulation}

The mechanisms regulating urea, glutamine and ammonia metabolism have been described in isolated organ preparations, isolated cells or mitochondria. These studies on isolated kidney and liver preparations have demonstrated that both organs exhibit, independently of each other, regulatory properties with respect to the maintenance of $\mathrm{pH}$ homeostasis: $\mathrm{HCO}_{3}^{-}$disposal is regulated in a sensitive way by a sophisticated interaction of hepatic urea synthesis and the alternative pathway of ammonium detoxication by glutamine synthesis. Renal ammoniagenesis guarantees the excretion of waste nitrogen as $\mathrm{NH}_{4}^{+}$ into urine when the $\mathrm{pH}$ situation does not allow further $\mathrm{HCO}_{3}^{-}$consumption by means of urea formation. This interorgan team effort not only involves nitrogen fluxes, but also carbon fluxes, resulting in a shift of gluconeogenesis from the liver to the kidney in acidosis. Only a few studies have documented the validity of the above concept under in vivo conditions. Recent studies in rats, dogs and humans have confirmed the concept, that acid base regulation involves liver and kidney nitrogen balances. By combination of blood flow measurements and determination of arteriovenous concentration differences of ammonium, glutamine and urea, interorgan regulation of these compounds has been documented (18, $33,57)$.

Under normal postabsorptive conditions, muscle is the main source of amino acid nitrogen including glutamine. Part of the glutamine is degraded by the gut, raising portal venous glutamate and ammonium (58). Glutamine, glutamate and ammonium nitrogen are incorporated into hepatic urea, which represents more than $95 \%$ of urinary nitrogen excretion.

Respiratory acidosis does not markedly change this situation. Urea formation decreases and liver glutamine uptake switches to glutamine release only under conditions of reduced bicarbonate levels (metabolic acidosis (fig. $5 \mathrm{a})$ ) $(18,33)$. Simultaneously the renal proximal tubule increases glutamine uptake and deamination, releasing ammonium into the urine (fig. $5 \mathrm{~b}$ ). This leads to a quantitative switch of whole body nitrogen excretion from urea to ammonium, as nicely shown in the early studies of Benedict (19). Conversely, metabolic alkalosis, which has been studied only in a few cases, leads to the opposite situation with a high hepatic ureagenesis and low renal ammoniagenesis (fig. 5c, d) (60). The concerted regulation of muscle proteolysis, gut and renal glutaminase, hepatic glutamine synthesis and uptake and urea synthesis explains why glutamine levels are either unchanged (33) or decreased $(19,53)$ under acidotic conditions. The inverse regulation of hepatic and renal gluconeogenesis may explain why renal gluconeogenesis contributes up to $50 \%$ of whole body glucose under chronic acidotic conditions (61) whereas its contribution is normally of minor importance.

In addition to these mechanisms, nitrogen-free metabolites may modify the glutamine nitrogen flux under acid-base-regulated conditions. Thuis ketone bodies, which by themselves are a major cause of metabolic acidosis inhibit renal glutamine metabolism and ammoniagenesis $(62,63)$. This effect leads to a sparing of nitrogen, which may be needed under conditions of limited protein supply. Lactate on the other hand leads to a reduction of liver and kidney glutamine metabolism $(63-65)$.

\section{Clinical considerations}

The mechanisms suggested by experimental data from animal and human studies can help to interpret changes observed in various diseases.

\section{Liver insufficiency}

A decrease in whole liver mass or function not only leads to a decreased urea cycle capacity, but simultaneously results in metabolic alkalosis (66). Observations in liver cirrhosis point to the quantitative importance of hepatic ureagenesis in preventing accumulation of bicarbonate during enteral protein reabsorption or parenteral amino acid infusion. Consequently a decrease of alimentary protein may help to prevent alkalosis.

\section{Negative nitrogen balance}

Under catabolic conditions (post-operative, malnutrition, cachexia) endogenous protein of muscle is de= graded and may lead to a negative nitrogen balance. This nitrogen is either excreted as urea or ammonium depending on the acid base condition and the composition of nutrition. During carbohydrate feeding, alanine is expected to be a major nitrogen carrier from muscle to liver (so-called Felig-cycle) supporting hepatic but not renal gluconeogenesis and consequently ureagenesis (67). Under low carbohydrate or ketogenic conditions, on the other hand, the contribution of the alanine cycle decreases, and hepatic glutamine formation becomes increasingly significant. In accordance with this hypothesis starvation and diabetes lead to a decrease in urea formation and a concomitant fractional increase in renal ammonium excretion $(2,33,68)$. 


\section{Ketoacidosis and lactate acidosis}

A similar change in the composition of urea nitrogen components can be expected in various forms of metabolic acidosis. When treated with bicarbonate renal ammoniagenesis is blocked and liver ureagenesis is expected to increase.

\section{Effect of diuretics}

Sulphonamide type diuretics like thiazides, xipamide, mefruside, chlortalidon and acetazolamide are expected to decrease liver ureagenesis by inhibition of mitochondrial carbonic anhydrase (69). This may explain the diuretic-induced hyperammonaemia and metabolic alkalosis especially in liver diseased patients.

\section{References}

1. Walter, F. (1877) Arch. Exp. Pathol. 7, 148-178.

2. Pincussen, L. (1928) Chemie der Niere und Harnwege. In: Handbuch der Biochemie, Vol. V (Oppenheimer, C., ed.) pp. $437-583$.

3. Pitts, R. F. (1936) J. Clin. Invest. 15, 571- 575 .

4. Pitts, R. F. (1973) In: Handbook of Physiology. Sect. 8 Renal Physiol. (Orloff, J. \& Berliner, R. W., eds.) Amer. Physiol. Soc. Washington, pp. 455-496.

5. Cahill, G. F. jr. (1970) New Engl. J. Med. 282, 668-675.

6. Pohl \& Münzer, E. (1906) Zbl. Physiol. 20, 232.

7. Oliver, J. \& Bourke, E. (1975) Clin. Sci. Mol. Med. 48, $515-520$.

8. Atkinson, D. E. \& Camien, M. N. (1982) Curr. Top. Cell. Reg. 21, 261-302.

9. Atkinson, D. E. \& Bourke, E. (1984) Trends Biochem. Sci. 9, 297-300.

10. Häussinger, D., Gerok, W. \& Sies, H. (1984) Trends Biochem. Sci. 9, 300-302.

11. Häussinger, D., Gerok, W. \& Sies, H. (1986) Biochem. J. $236,261-265$.

12. Welbourne, T. C. \& Phromphetcharat, V. (1984) In: Glutamine metabolism in mammalian tissues (Häussinger, D. \& Sies, H., eds.) Springer Verlag Berlin, pp. 161-177.

13. Walser, M. (1986) Am. J. Physiol. 250, F181-F188.

14. Vinay, P., Gougoux, A. \& Halperin, M. (1985) Medicine/ Sciences $85,30-35$.

15. Halperin, M. L. \& Jungas, R. L. (1983) Kidney Int. 24, 709-713.

16. Silbernagl, S. \& Scheller, D. (1986) Klin. Wochenschr. 64, 862-87.0.

17. Halperin, M. L., Chen, C. B., Cheema-Dhadli, S., West, M. L. \& Jungas, R. L. (1986) J. Clin. Chem. Clin. Biochem. 24, 267.

18. Welbourne, T. C. (1986) Biol. Chem. Hoppe-Seyler 367, $301-305$.

19. Benedict, S. R. \& Nash, T. P. (1929) J. Biol. Chem. 82, $673-678$.

20. Ross, B. \& Lowry, M. (1981) In: Renal Transport of Organic Substances (Greger, R., Lang, F. \& Silbernagl, S., eds.) Springer, Heidelberg, pp. 78-92.

21. Lemieux, G., Vinay, P. \& Cartier, P. (1974) J. Clin. Invest. $53,884-894$.

22. Pilkington, L. A., Young, T.-K. \& Pitts, R. F. (1970) Nephron 7, 51-60.

23. Davies, A. C. \& Yudkin, J. (1952) Biochem. J. 52, 407412.

\section{Outlook}

The present concept, although still in dispute (711), offers explanations for several well documented relations between nitrogen metabolism and acid base disturbances. Until now only limited studies have considered this interrelationship. It is hoped therefore that the present review will help to stimulate future studies to confirm the clinical significance and therapeutic implications of these mechanisms.

\section{Acknowledgement}

The authors gratefully acknowledge the assistance of $\mathrm{Mr}$. $T / t$. Stchle and Mrs. E. Vollrath during preparation of this manuscript. Our own work herein reported was supported by the Deutsche Forschungsgemeinschaft (project Gu $82 / 2$ and the Sonderforschungsbereich 154, Experimentelle und klinische Hepatologie) and the Heisenbergprogramm.

24. Goldstein, L. (1976) Biochem. Biophys. Res. Comm. 70, 1136- 1141.

25. Vinay, P., Lemieux, G., Gougoux, A. \& Halperin, M. (1986) Kidney Int. 29, 68-79.

26. Guder, W. G. \& Ross, B. D. (1984) Kidney Int. 26, $101-111$.

27. Curthoys, N. P. \& Lowry, O. H. (1973) J. Biol. Chem. 248, $162-168$.

28. Nonoguchi, H., Uchida, S., Shiigai, T. \& Endou, H. (1985) Pflügers Arch. 403, 229-235.

29. Good, D. W. \& Burg, M. B. (1984) J. Clin. Invest. 73, 602-610.

30. Garvin, J. L., Burg, M. B. \& Knepper, M. A. (1985) Am. J. Physiol. 249, F785-F788.

31. Good, D. W. \& Knepper, M. A. (1985) Am. J. Physiol 248, F459-F471.

32. Burch, H. B., Choi, S., Mc Carthy, W. Z., Wong, P. Y. \& Lowry, O. H. (1978) Biochem. Biophys. Res. Comm. 82, $498-505$.

33. Schrock, H. \& Goldstein, L. (1981) Am. J. Physiol. 240, E519-E525.

34. Tannen, R. L. \& Ross, B. D. (1979) Clin. Sci. 56, 353364.

35. Mc Farlane-Anderson, N. \& Alleyne, G. A. O. (1979) Biochem. J. 182, 295-300.

36. Schoolwerth, A. C. \& LaNoue, K. F. (1985) Ann. Rev. Physiol. 47, 143-171.

37. Guder, W. G. \& Pürschel, S. (1980) Int. J. Biochem. 12, 63-68.

38. Lowry, M. \& Ross, B. D. (1980) Biochem. J. 190, $771-$ 780.

39. Schoolwerth, A. C. (1986) J. Clin. Chem. Clin. Biochem. 24, 259 (abstr.).

40. Wirthensohn, G. \& Guder, W. G. (1986) Physiol. Rev. 66, 469-497.

41. Kamm, D. E. \& Strope, G. L. (1974) Metabolism 23, 1073-1074.

42. Forissier, M., Baverel, G. (1981) Biochem. J. 200, 27-33.

43. Ross, B. D. (1976) Clin. Sci. Mol. Med. 50, 493-498.

44. Vinay, P., Lemieux, G., Gougoux, A. \& Watford, M. (1978) Proc. VIIth Int. Congr. Nephrol. Karger, Basel, pp. 199207.

45. Preuss, H. G., Baird, K. \& Golding, H. (1974) J. Lab. Clin. Med. 83, 937-946.

46. Preuss, H. G., Vivatsi-Manos, O. \& Vertuno, L. L. (1973) J. Clin. Invest. 52, 755-764. 
47. Manillier, C., Vinay, P., Laloude, L., Noel, J., Gougoux, A. \& Halperin, M. L. (1985) In: New Advances in Renal Ammonia Metabolism (Schoolwerth, A. C., Kurokawa, K., Tannen, R. L. \& Vinay, P., eds.) Karger, Basel, pp. 78-86.

48. Häussinger, D. (1983) Eur. J. Biochem. 133, 269-275.

49. Häussinger, D. (1986) Adv. Enz. Reg. 25, 159-180.

50. Wanders, R. J. A., Van Roermund, C. W. T. \& Meijer, A. J. (1984) Eur. J. Biochem. 142, 247-254.

51. McGivan, J. D., Bradford, N. M., Verhoeven, A. J. \& Meijer, A. J. (1984) In: Glutamine Metabolism in Mammalian Tissues (Häussinger, D. \& Sies, H., eds.) Springer Verlag Berlin, pp. 122-137.

52. Häussinger, D., Gerok, W. \& Sies, H. (1983) Biochim. Biophys. Acta 755, 272-278.

53. Häussinger, D. \& Gerok, W. (1985) Eur. J. Biochem. 152, $381-386$.

54. Chappell, J. B. \& Crofts, A. R. (1966) In: Regulation of Metabolic Processes in Mitochondria (Tager, J. M., Papa, S., Quagliariello, E. \& Slater, E. C., eds.) Elsevier, Amsterdam, pp. 292-314.

55. Remesy, C., Demigne, D. \& Farfournoux, P. (1986) Eur. J. Biochem. 158, 283-288.

56. Cohen, N. S., Kyan, F. S., Kyan, S. S., Cheung, C. W. \& Raijman, L. (1985) Biochem. J. 229, 205-211.

57. Tizianello, A., Deferrari, G., Garidotto, G., Robando, C., Bruzzone, M. \& Passerone, G. C. (1982) Contr. Nephrol. $31,40-46$
58. Windmueller, H. G. \& Spaeth, A. E. (1975) Arch. Biochem Biophys. 17, 662-672.

59. Baverel, G. \& Lund, P. (1979) Biochem. J. 184, 599-606.

60. Lemieux, G., Junco, E., Lemieux, C., Joffre, R., Perez, R., Kjss, A. L. \& Aranda, M. R. (1985) In: "Kidney Metabolism and Function" (Dzurik, R., Lichardus, B. \& Guder, W. G., eds.) Martinus Nijhoff Publ., Dordrecht, pp. 17-25.

61. Yudkin, J. \& Cohen, R. D. (1975) Clin. Sci. Mol. Med. 48, $121-131$.

62. Lemieux, G., Vinay, P., Robitaille, P., Plante, G, F., Lussier, Y. \& Martin, P. (1971) J. Clin. Invest. 50, $1781=1791$.

63. Guder, W. G., Wagner, S., Wirthensohn, G. (1986) Kidney Int. $29,41-45$.

64. Guder, W. G. \& Wirthensohn, G. (1979) Europ. J. Biochem. $99,577-584$.

65. Wirthensohn, G., Brocks, D. G. \& Guder, W. G. (1980) Hoppe Seyler's Z. Physiol. Chem. 361, 985-993.

66. Dölle, W. (1965) Der Säurebasenstoffwechsel bei Lèberzirrhose, Dr. A. Hüthig Verlag, Heidelberg.

67. Felig, P. (1975) Ann. Rev. Biochem. 44, 933-955.

68. Wahren, J., Felig, P., Cerasi, E. \& Luft, R. (1972) J. Clin. Invest. $51,1870=1878$.

69. Häussinger, D., Kaiser, S., Stehle, Th. \& Gerok, W. (1986) Biochem. Pharmacol. 35, 3317-3322.

Professor Dr. W. G. Guder

Städt. Krankenhaus München-Bogenhausen Institut für Klinische Chemie

Englschalkinger Straße 77

D-8000 München 81 